\title{
The Significance of Light in the Near-Death Experience
}

\author{
T. Lee Baumann, M.D. \\ Birmingham, $A L$
}

ABSTRACT: Light has long been recognized as a principal characteristic of the near-death experience (NDE). However, its significance has been widely debated. This paper details the significance of light in the NDE, and it further suggests that science supports the contention that the light of the NDE represents the presence of a loving and concerned Creator. I cite wellestablished and celebrated physics experiments to support the argument that light exhibits supernatural - even conscious - qualities. The relationship of light to the NDE, quantum physics, and descriptions of God throughout the world's literature serve to illuminate the argument that God and the light may well be one and the same.

KEY WORDS: near-death experience, light, quantum physics, science, spirituality.

In 1975, the year Raymond Moody's Life After Life was first published, I was starting my last year of medical school. At that time in my life, I was still much a religious skeptic, being firmly in the grasp of Charles Darwin's evolutionary influence, my medical and biological training, and the scientific method. Today, I still uphold my conviction in the importance of the scientific method, but, instead of it separating me further from spirituality, it has made me a believer.

The two individuals that I credit most for this transformation are philosopher and physician Raymond Moody and physicist and Nobel Prize winner Albert Einstein. These two individuals played very divergent yet complementary roles in this process. In addition, their undisputed credibility in their respective fields convinced me of the legitimacy of their arguments.

T. Lee Baumann, M.D., is an author and medical consultant in Birmingham, AL. Reprint requests should be addressed to Dr. Baumann at 3805 Kinross Drive, Birmingham, AL 35242-5803; e-mail: tbaumann1@yahoo.com. 


\section{Light's Omnipresence, Omniscience, and Omnipotence}

In 1975, I had already developed a fascination for Einstein's work, especially his special theory of relativity. As a religious skeptic, I was nonetheless enthralled by the mysterious nature of the photon as depicted by Einstein's quantum revolution. I found something ethereal and supernatural in the photon, a coexistent wave and particle, for which time ground to a halt. As several scientists have concluded, this feature alone allowed the photon to be literally everywhere in the universe at once - that is, to be omnipresent (Gribbin, 1984). Allow me to explain.

Imagine if you will that, at 1000 B.C., a photon emerged from Star A. Visualize now, some 3000 years later, that the same photon passes by planet Earth. Although 3000 years have elapsed in our human recognition of time, no time at all has transpired for the photon. Theoretically, it is conceivable for that photon to traverse the entire universe in zero time. Not only that, but the photon can do it repeatedly! In this manner, the photon can be literally everywhere in the universe at once. This is not just scientific theory; it is proven fact.

Oddly, a direct ramification of light's omnipresence is the attribute of omniscience or absolute knowledge. Consider that any entity that exists everywhere in the universe at the same time - and for which time does not exist - has immediate access to everything that has ever happened in the past, everything that is happening now, and everything that will occur in the future (Baumann, 2002). Hence, the photon is also all-knowing.

The relationships only continued to grow. Moody, in his second book, Reflections on Life After Life (1977), further identified the occasional association of absolute knowledge with the $\mathrm{NDE}$, which then disappeared upon the victim's return to the body. Certainly, this coincided nicely with the presence of light in the NDE and science's implied omniscience of light. If acceptance of these concepts seems extreme, one only has to review the proven slowing of time in Einstein's traveling-twin paradox, in which one twin travels at close to light speed. In this well-accepted illustration, physics demonstrates that travel near the speed of light can and will delay relative aging. I refer skeptics to the observed longevity of muons entering the Earth's atmosphere as to the validity of this observation.

Let us assume that there are a pair of twins, A and B. Twin A will travel to star $\mathrm{Z}$, which is 10 light-years away, and return home to Earth, for a total distance of 20 light-years roundtrip. Twin B will 
remain on Earth and not travel at all. If twin $A$ travels to star $\mathrm{Z}$ at 80 percent of the speed of light $(0.8 \mathrm{c})$, then let us calculate the apparent time necessary to complete the journey - that is, the time it would take if the slowing of time due to twin A's fractional light-speed travel were not considered. This time would also be the observed time for twin B, remaining on Earth, to measure twin A's complete trip. Since we know that twin $A$ is traveling slower than light-speed, we can anticipate that the resulting time will be greater than 20 years. Specifically, since distance equals velocity multiplied by time $(d=v t)$, then time equals distance divided by velocity. In this example, the observed time for twin $\mathrm{B}$ equals the distance ( 20 light-years) divided by the velocity ( 0.8 c), or $20 / 0.8=25$ years. In other words, 25 years is the time that twin $B$ ages while waiting for twin A to complete the journey.

Now let us calculate the actual duration of the roundtrip as timed by twin A on the journey, taking into account the factor of time dilation as first expounded by Einstein. Since we know that this type of travel will slow time for twin A, we can expect that the result will be less than 25 years. Let us see if that holds true. Time dilation, according to Einstein's equation, equals observed time multiplied by the square root of 1 minus velocity squared $\left(T^{\prime}=t\left[1-v^{2}\right]^{1 / 2}\right)$. In this example, then, time for the traveling twin A equals 25 years multiplied by the square root of $\left(1-0.8^{2} \mathrm{c}\right)$, or 15 years. Thus, 15 yrs is the actual time it takes twin A to complete the roundtrip! Travel at close to light-speed really does slow time and aging.

Twin $B$ remaining on Earth, however, will have aged 25 years compared to twin $A$, who is now 10 years younger! This case strikingly illustrates how fractional light-speed travel really does diminish aging and slows time. This is not just an illusion brought about by an apparent slowing of time in one twin. Time, in fact, does slow down. If we were to perform the same calculations, but for twin A's speed of travel increased to actual light-speed c, twin A's actual time for the trip is found to contract all the way to zero. That is, time stops completely.

Finally, the third and last "omni-," omnipotence, is illustrated by the controversial mathematical technique known as renormalization, employed routinely by physicists, which implies that the energy of the photon is infinite (Gribbin, 1984). This technique resulted from the unacceptable infinities that kept presenting themselves in early computations to determine the energy levels of electrons and atoms. The culprit behind the resulting infinities was none other than the extraordinary photon. In retrospect, the infinities were arising from 
the inescapable and intimate relationship that atoms and electrons have with light. It is the photon that gives an electron the necessary energy to jump to a higher orbital level in the atom. Conversely, it is the photon that must be discharged from the electron to allow it to descend to a lower electron orbit. Consequently, physicists found it impossible to determine the energies of atoms or electrons without also including the energies of photons.

After much hardship, mathematicians finally developed a technique known as renormalization to successfully eliminate these infinities from the equations. The controversy over this technique arises from the fact that not all physicists are satisfied with the method, some referring to it as a mathematical "trick" or "sleight of hand." The necessity for this technique, however, leads some to deduce that light, similar to descriptions of God, is infinite in power or omnipotent. Others merely deduce that any entity that can exist everywhere in the universe at once, and for which time stops, must possess infinite energy.

One further concept, which I term the "alpha and omega," shows how science has again demonstrated a corollary linking light to descriptions of God. Cosmologists postulate that one of the first constituents liberated at the moment of the Big Bang (alpha) was light. Similarly, scientists hypothesize one of two possible endings to our universe. In one, the universe is visualized as collapsing in upon itself (the Big Crunch), not unlike a replay of the Big Bang in reverse. In the other, the universe is seen dying a cold death as it forever continues to expand, with all matter eventually decomposing over billions of years into only neutrinos and photons. In either of these two scenarios depicting the final days, light is witnessed as one of the (if not the) final universal remnant (omega).

\section{Light's Consciousness}

To make matters still more confusing to my young, medically inclined mind, science experiments were unveiling more puzzling qualities to our universe. The double-slit and related series of experiments were attributing behavior to the photon that physicists were even describing as "conscious" (Zukav, 1979). In this puzzling series of experiments, light waves anticipated modifications in the experimental setup before they reached them and altered their behavior accordingly. The related experiment that most clearly and 
simply displays this trait is the quantum eraser experiment. In layperson's terms, in the unmodified experiment, a photon enters an experimental set-up and scientists observe the photon's course of action. However, in the same experiment but with a modified final stage, the photon alters its course of action before reaching the last stage, and then passes through the modified final stage.

You could not reasonably argue that that the photons were reacting in response to the experimental changes because they had not yet reached that juncture of the experiment. The only plausible explanation, however, lies in the realization that time does not exist for rays of light. The photons actually did reach the changes in the experimental set-up, but then they did something remarkable. The photons then traveled back in time, and then they altered their course of action. To the human observer, we perceived this as the photons divining the experimental changes in advance, and then reacting to them midway through the experiment!

Physicist and Nobel Prize winner Richard Feynman exemplified scientists' confusion when he made the following comment regarding this enigmatic experiment:

[The double-slit experiment is] a phenomenon which is impossible, absolutely impossible, to explain in any classical way, and which has in it the heart of quantum mechanics. In reality, it contains the only mystery ... the basic peculiarities of all quantum mechanics. (Feynman, Leighton, and Sands, 1963, p. 372)

\section{Other Scientific Elements Supporting Metaphysical Phenomena}

All of the observations made up to this point have suggested intriguing comparisons between the baffling photon and a Supreme Being. Indeed, there are numerous other scientific arguments supporting paranormal phenomena and intelligent design in our universe.

The second law of thermodynamics, also known as entropy, suggests a designing hand in the formation of the universe at the time of the Big Bang. This well-proven law of nature states that the universe is continually, over time, progressing towards increased disorder. When viewed in reverse, however, the converse is also true. As you progress backwards through time, the universe displays increasing order. This reverse progression, all the way back to the beginning of the universe, indicates that an infinite amount of order or design existed at the time of the creation of the universe (Penrose, 1989). 
An additional physics experiment implies the existence of two "supernatural" qualities to our universe. In this experiment, two identical photons are emitted from an atom and observed. This EPR experiment (named after its physicist inventor Einstein and his two postdoctoral research associates Boris Podolsky and Nathan Rosen) revealed two new peculiarities to the cosmos. First, our actions on Earth are causing proven changes (albeit, unknown) in other parts of the universe; and second, superluminal (faster than light) communication really exists (Herbert, 1985). These outcomes would prove exceptionally important in explaining several features of certain paranormal phenomena, including the instantaneous nature of the NDE and some death-related visions.

If all these findings were not surprising enough, research performed at the National Institute of Standards and Technology established that human observation could alter (specifically, delay) the outcome of a unique physics experiment performed at that institution (Gribbin, 1995). This experiment determined that human consciousness holds a very unique and special role in the overall functioning of our universe. Further research is needed to determine whether this distinction holds true for other animal species as well. Certainly, this experiment (along with the mysterious attributes of light) offers an additional, valuable piece to the profound puzzle that is the human psyche.

Those who find the above experiments too remarkable to believe need not feel alone. Even the world's leading physicists have expressed astonishment. Danish physicist and Nobel Prize winner Niels Bohr noted, "Those who are not shocked when they first come across quantum theory cannot possibly have understood it" (Goswami, Goswami, and Reed, 1993, p. 73).

Not only is classical Newtonian physics seen to be losing ground to the new arena of quantum mechanics, but this "new physics" appears to be supporting the existence of a higher intelligence and proffering a new credibility to particular metaphysical phenomena. By the time I had settled into my medical practice some years later, all the necessary information for this understanding was at my disposal. The elements of the near-death experience (NDE) that Moody had outlined in his books served to catalyze my final revelation. Fellow physician Melvin Morse summarized the situation well when he observed, "I have found the experience of light to be the keynote event of the near-death experience, the element that always leads to a transformation" (Morse and Perry, 1992, p. 196). I realized that light was the unifying factor supporting all these major events: Einstein's theories, the quantum 
physics revolution, the NDE, some psychic and paranormal phenomena, and the ultimate manifestation of God on Earth!

For those who feel that the last connection was an insurmountable leap, I ask you only to consider the following question: In what terms is God described in every major religious text throughout the world? The answer, you will find, is readily apparent: Light. Take, for example, some of the following citations from some of the world's most recognized religious texts:

Bless the Lord, O my soul!

O Lord my God, thou art very great!

Thou art clothed with honor and majesty, who coverest thyself with light as with a garment. (Psalms 104: 1-2)

Again Jesus spoke to them, saying, "I am the light of the world; he who follows me will not walk in darkness, but will have the light of life." (John 8: 12)

This is the message we have heard from him and proclaim to you, that God is light and in him is no darkness at all. (I. John 1: 5)

For she [wisdom] is a reflection of the everlasting light, And a spotless mirror of the activity of God (Apocrypha: The Wisdom of Solomon)

All around you $\rightarrow$ in every corner and on every side - is light. Turn to your right, and you will find shining light; to your left, splendor, a radiant light. Between them, up above, the light of the Presence. Surrounding that, the light of life. Above it all, a crown of light ... This light is unfathomable and endless. (Kabbalah, "Mind, Meditation, and Mystical Experience")

God is the light of the heavens and the earth. His light may be compared to a niche that enshrines a lamp, the lamp within a crystal of star-like brilliance. It is lit from a blessed olive tree neither eastern nor western. Its very oil would almost shine forth, though no fire touched it. Light upon light; God guides to His light whom He will. (Koran 24: 35)

The Blessed One said: ...

I am light in the moon and sun ...

And brilliance in fire am I,

Life in all beings,

And austerity in ascetics am I. (Bhagavad Gita, VII: 8-9)

But were the spiritual comparisons of God to light only meant to be metaphorical? Any questions I initially had were quickly dispelled 
once I began researching light's multiple idiosyncrasies. In the NDE, light represented God, Christ, or a spiritual guide, depending on the victim's religious convictions, but a heavenly and spiritual guide nonetheless. Science had already provided me with the unexpected revelations of light's omnipresence, omniscience, omnipotence, and consciousness. Everything pointed neatly in light's unifying direction. In fact, if one closely examines Einstein's $E=\mathrm{mc}^{2}$ equation, it is logical to see that $m$, which is mass or matter, is a transmutation of $\mathrm{E}$, which is pure energy or light. With this equation, it becomes easier to visualize the Eastern religious philosophy that God really is everything.

\section{Conclusion}

Other scientists and authors have discussed many of these concepts, offering fresh perspectives that contributed to this melding of scientific discovery and spiritual conviction (Davies, 1982, 1983; Gribbin, 1984, 1995; Greene, 1999; Herbert, 1985; Schroeder, 1997; Templeton, 1994, 1995; Zukav, 1979). By the time I had completed my research and embarked on writing God at the Speed of Light (2001), there was no longer any doubt in my mind. Earlier, science had been my spiritual adversary. Now, it was my champion. If Light was not literally the embodiment of God, the two were certainly intimately related. My subsequent investigations have only confirmed these earlier findings. For instance, some past-life regressions and clairvoyant pathways have also followed "the light" (Baumann, 2005).

Science stands at the threshold of validating the Creator's existence. Raymond Moody and the NDE were crucial catalysts in this revelation. Because $\mathrm{E}$, representing the pure energy of Light and God, equals $\mathrm{mc}^{2}$, then truly, God is all things, and, together with light, is uniquely omnipresent, omniscient, and omnipotent, making God and Light understandable features of the near-death experience.

\section{References}

Baumann, T. L. (2001). God at the speed of light: The melding of science and spirituality. Virginia Beach, VA: A.R.E. Press.

Baumann, T. L. (2005). Window to God: A physician's spiritual pilgrimage. Virginia Beach, VA: A.R.E. Press.

Davies, P. (1982). The accidental universe. New York, NY: Cambridge University Press. Davies, P. (1983). God and the new physics. New York, NY: Simon and Schuster. 
Feynman, R. P., Leighton, R. B., and Sands, M. (1963). The Feynman lectures on physics, Reading, MA: Addison-Wesley.

Goswami, A., Goswami, M., and Reed, R. E. (1993). The self-aware universe: How consciousness creates the material world. New York, NY: Tarcher/Putnam.

Gribbin, J. R. (1984). In search of Schrödinger's cat: The startling world of quantum physics explained. London, England: Wildwood House.

Gribbin, J. (1995). Schrodinger's kittens and the search for reality: Solving the quantum mysteries. Boston, MA: Little, Brown.

Greene, B. (1999). The elegant universe: Superstrings, hidden dimensions, and the quest for the ultimate theory. New York, NY: Vintage Books.

Herbert, N. (1985). Quantum reality: Beyond the new physics. New York, NY: Anchor Books.

Moody, R. A. (1975). Life after life. Covington, GA: Mockingbird Books.

Moody, R. A. (1977). Reflections on life after life. St. Simon's Island, GA: Mockingbird Books.

Morse, M. L., and Perry, P. (1992). Transformed by the light: The powerful effects of near-death experiences on people's lives. New York, NY: Villard.

Penrose, R. (1989). The emperor's new mind. New York, NY: Penguin.

Schroeder, G. L. (1997). The science of God. New York, NY: Free Press.

Templeton, J. M. (ed.). (1994). Evidence of purpose: Scientists discover the Creator. New York, NY: Continuum Publishing.

Templeton, J. M. (ed.). (1995). The humble approach: Scientists discover God. New York, NY: Continuum Publishing.

Zukav, G. (1979). The dancing wu li masters: An overview of the new physics. New York, NY: Morrow. 